\title{
Tim Brown, Change by Design: How Design Thinking Transforms Organizations and Inspires Innovation (2009)
}

\author{
Esra Gonen \\ Izmir University of Economics
}

Follow this and additional works at: https://digitalcommons.uri.edu/mgdr

Part of the Business Administration, Management, and Operations Commons, Industrial and Product Design Commons, Marketing Commons, and the Other Business Commons

\section{Recommended Citation}

Gonen, Esra (2019) "Tim Brown, Change by Design: How Design Thinking Transforms Organizations and Inspires Innovation (2009)," Markets, Globalization \& Development Review. Vol. 4: No. 2, Article 8. DOI: 10.23860/MGDR-2019-04-02-08 Available at: https://digitalcommons.uri.edu/mgdr/vol4/iss2/8

This Book Review is brought to you for free and open access by DigitalCommons@URI. It has been accepted for inclusion in Markets, Globalization \& Development Review by an authorized editor of DigitalCommons@URI. For more information, please contact digitalcommons-group@uri.edu. 
Tim Brown, Change by Design: How Design Thinking Transforms Organizations and Inspires Innovation (2009)

\section{Markets, Globalization \& Development Review}
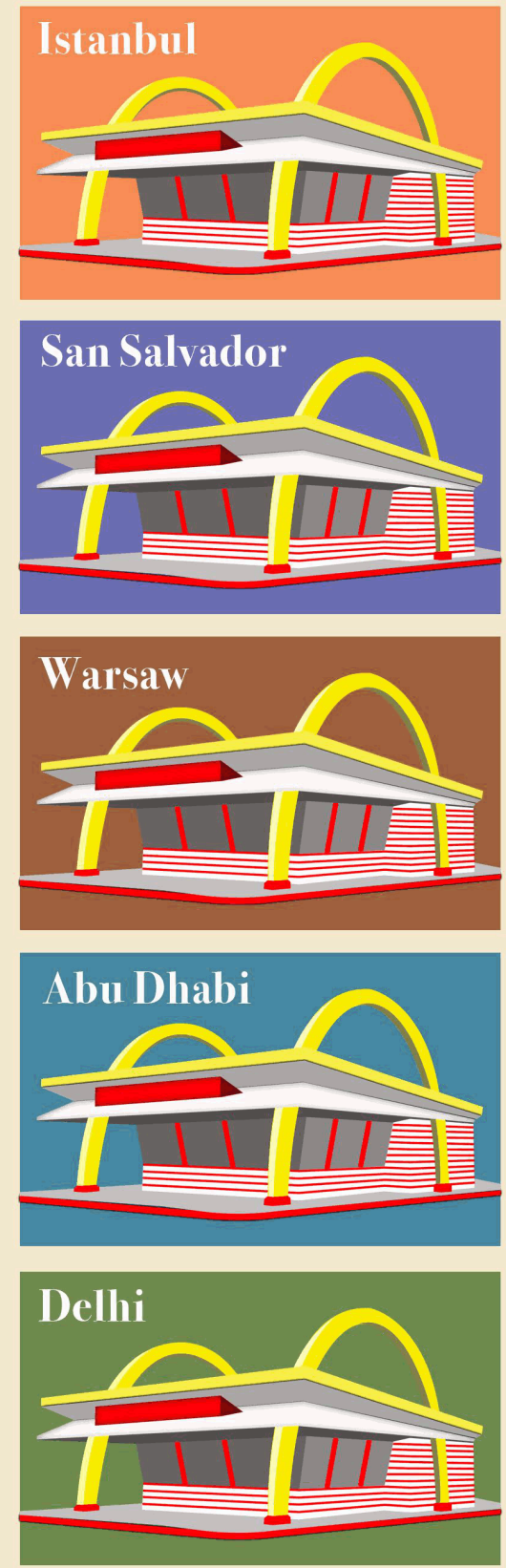
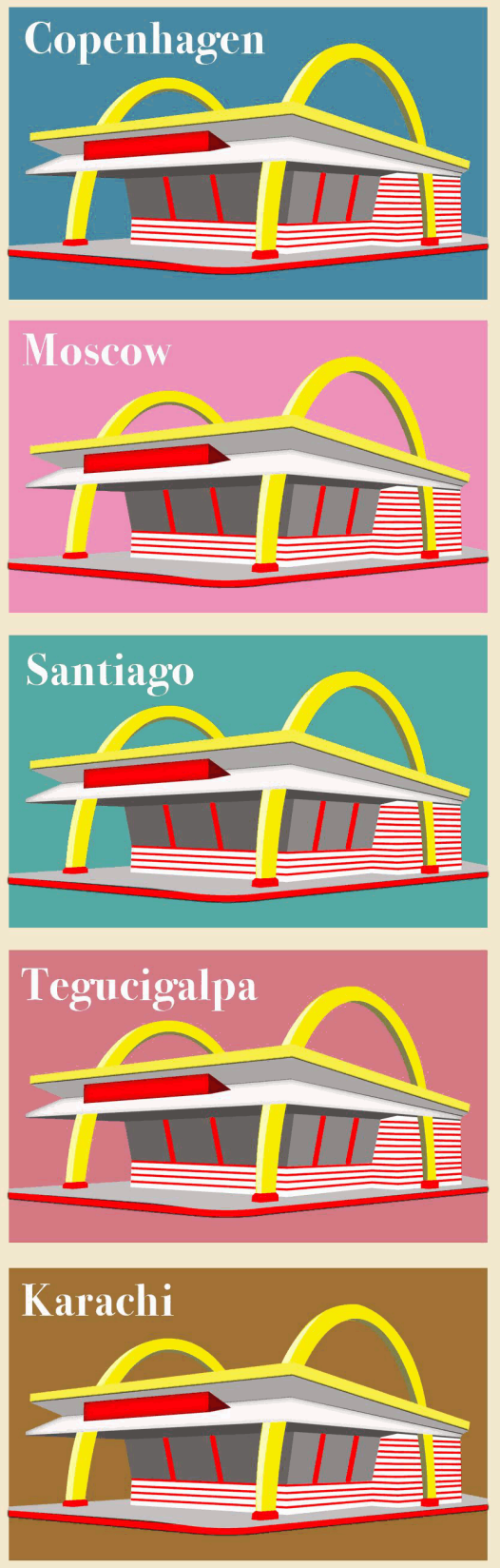
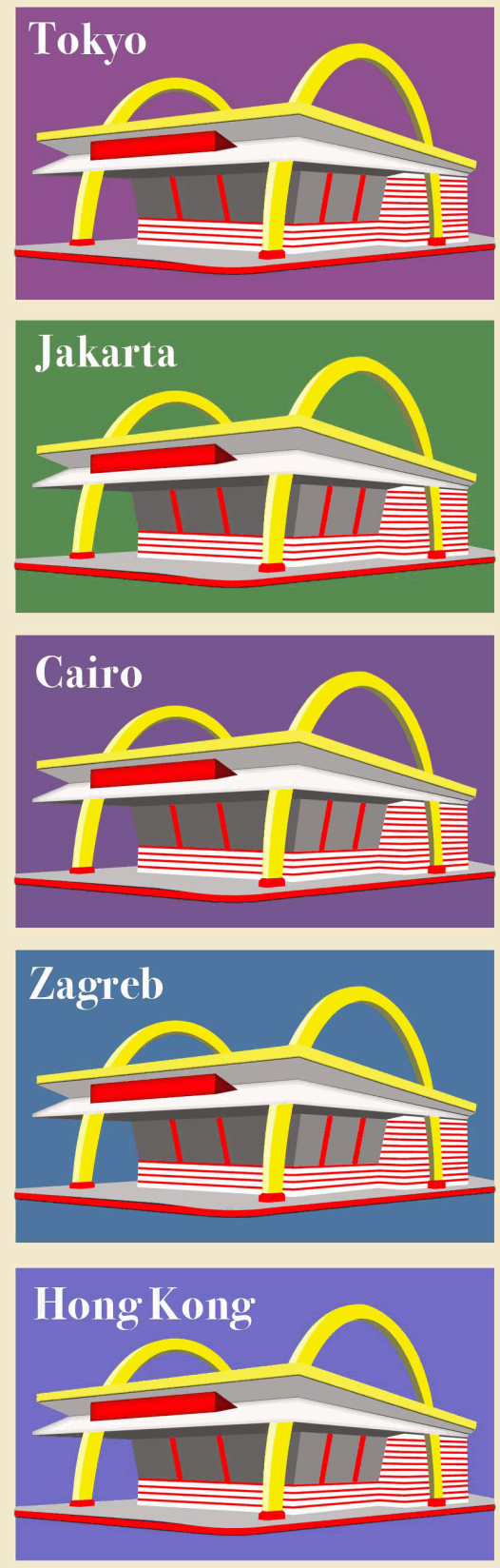

This book review is available in Markets, Globalization \& Development Review: https://digitalcommons.uri.edu/mgdr/ vol4/iss $2 / 8$ 


\section{Book Review \\ Tim Brown, Change by Design: How Design Thinking Transforms Organizations and Inspires Innovation (2009)}

\section{Introduction}

As for business leaders, 'Change by Design' could be considered as a reference book written by a designer; therefore, it is important to answer the question of 'why should I read a book from Tim Brown to transform my organization?' Yes, Tim Brown is a successful industrial designer with numerous design awards. However, his special interest is the integration of thinking skills of designers into all aspects of business, yet he frequently speaks about the value of design thinking and innovation to business people and designers around the world. Tim Brown, as the CEO and the president of IDEO (an important design and innovation company based in Palo Alto), advises senior executives and boards of Fortuna 100 companies and has led strategic client relationship with such corporations as Microsoft, PepsiCo, Procter \& Gamble, and Steelcase. He published other studies in this relation such as "We should design businesses like circles, not straight lines," in 2017 and "Design for Action," in 2015 in Harvard Business Review.

Although the author refers to many relevant academic studies from different domains such as phycology, sociology, business, engineering; the book, rather than being an academic work, is a persuasive type of writing, in which Tim Brown, with respect to his experience both as a designer and also a business consultant, tries to convince his reader about the change maker effect of Design Thinking for a company. For this purpose he uses many success stories, anecdotes about business interactions of his company IDEO and its well know clients. The reader learns what solutions IDEO reached by implementing Design Thinking, which might indeed make him/her perceive design thinking a luxury or complicated process since all companies in the showcases have big teams of designers and big budgets to be able to collaborate with IDEO.

Throughout the book the author emphasizes the importance of visual thinking for expressing ideas, on the contrary the book consists of almost no visuals. However, both the design and also the language used in the book, without heavy business jargon, make it easy to read and understand for the reader. 
On the back of the book jacket Brown states, 'this is not a book by designer for designers, this is a book for creative leaders who seek to infuse design thinking into every level of an organization'. However, the book also serves well for designers to recognize their possible contribution to other domains by the help of their designer skills, which could create alternative business or working models for them as well, even at the managerial level.

In the book, very often, we see that Brown compares traditional business thinking and strategies with design thinking as well as a traditional designer with a design thinker. This review of the book is also consists of relevant business tools / methodologies comparable or complementary with design thinking.

\section{Overview of the Contents of the Book}

\section{Problem Definition: Main Problem addressed in the Book}

Brown starts his book with a great example of an engineering and design excellence of Great Western Railway and its creator Brunel to underline the importance of design and technology in shaping our lives since the beginning of industrial revolution. However, he wants to take readers attention to so called multifaceted problems in today's world. The world has become faster not only in transportation but also, consumption (excess consumption), waste production, communication, competition that in turn threatens both our living environment but also our business environment. In such an environment he finds it insufficient to be dependent on purely a techno centric view of innovation and a management philosophy based on existing strategies and more importantly by ignoring human considerations. Yet he looks for a powerful, effective and creative approach for innovation.

Indeed, it is true that we are in a world where change is ever greater and the future is less predictable. It is becoming more and more challenging for business leaders to tackle with wicked problems in this increasingly complex environment with the increasing level of technology improving competition. Wickedness isn't a degree of difficulty; wicked issues are different because traditional processes can't resolve them (Camillus, 2008). Bennett and Lemoine (2014) similarly underline that globalization and technological advancements created opportunities with one hand as they have introduced threats with the other. In their study Bennett and Lemoine (2014) describe the trendy managerial acronym: VUCA world, short for volatility, uncertainty, complexity, and ambiguity. A world that requires the right framework conditions under which each individual may contribute his or her skills together with freedom, creativity, speed, flexibility and a corporate culture that connects people with the organization as explained 
by Waltraud Glaeser, a leadership consultant, as parallel to what Tim Brown designates in 'Change by Design'.

Source of the Problem: Competing Constraints

The main sources of the problem addressed in the book are the traditional approaches towards competing constraints for successful ideas (strategies). Brown, visualized constraints in three overlapping criteria: feasibility (what is functionally possible within the foreseeable future), viability (what is likely to become part of as sustainable business model); and desirability (what makes sense to people and for people). He finds it risky to be dependent on technical innovations to overcome feasibility constraint focusing near-term viability by avoiding unpredictable future. He also adds that existing business systems are designed for efficiency, so new ideas are tend to be incremental, predictable and easy for competition to emulate; therefore they will be viable but not really innovative. Lastly, and most importantly to depend on estimations and/or basic market research to determine the what makes sense for people undermines the sustainability of any outcome whether it is a product, service or a strategy. Here he doesn't mean only clients by saying people, rather he means people on the both sides of the table (both clients and designer team). Even in a broader sense, he gives importance to involvement of all stakeholders in decisionmaking process, which had been already introduced by Herbert Simon in his popular book 'The Sciences of the Artificial'.

In the presence of above mentioned fact about wicked problems and insufficiency of existing strategies to solve them, the author aims to introduce 'Design Thinking' as an approach for creative problem solving and to discover new alternatives for business and leadership by inspiring innovation.

The first half of the book consists of multiple cases, from HBO to Marriot Hotels that are all used to illustrate the skills, concepts and techniques that originated in the design community. However, Brown immediately puts design thinker apart from a designer starting from tackling with competing constraints, which are stated as main sources of the problem in the book. According to him 'A competent designer will resolve constraints, but a design thinker will bring them in harmonious balance. So, the willing of acceptance of competing constraints is the foundation of design thinking with an integrated approach. Like Cross (2001), positions design superior to science for achieving better solutions, with forms of knowledge peculiar to designers; Brown also positions a ideal designer (design thinker), who welcomes boundaries, apart from scientists and artists to whom such boundaries appear as unwelcome constraints. 
Design Thinking: Non-Linear, Interdisciplinary, Integrated, and Human-centered

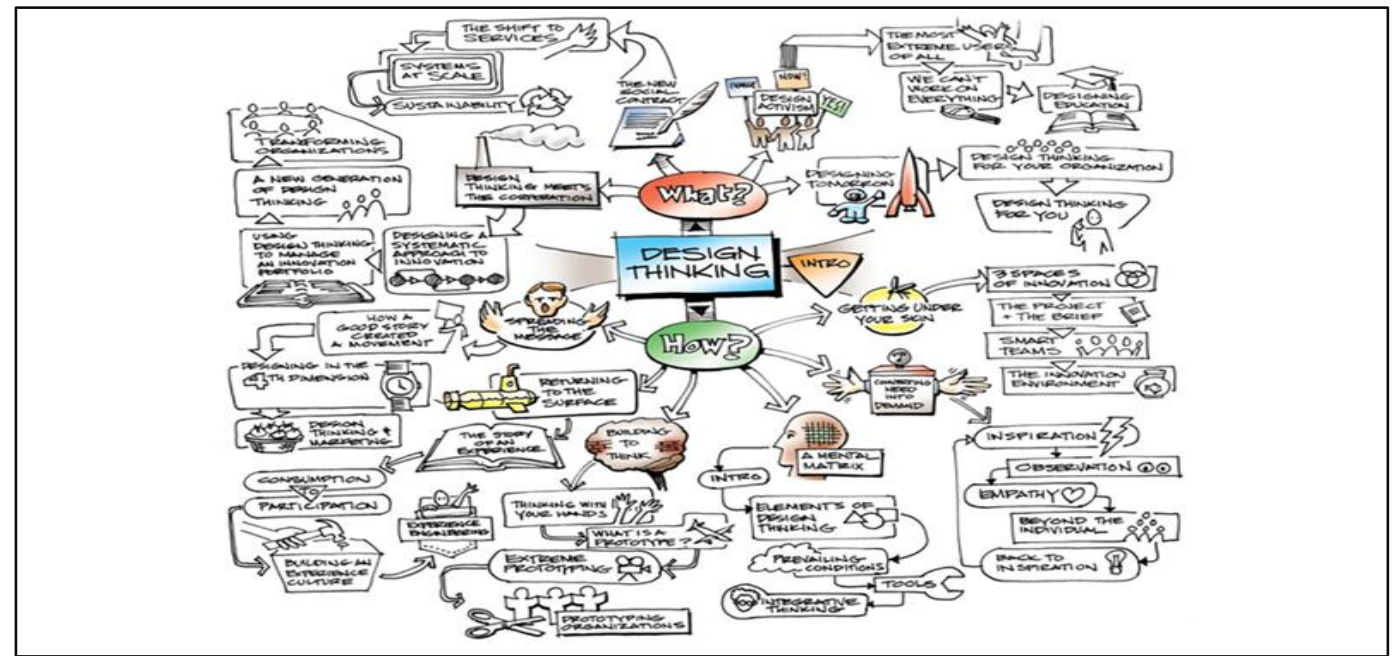

Source: Brown T., 2009, Change by Design: How Design Thinking Transforms Organizations and Inspires Innovation

The second core concept Brown emphasizes is the human centered design. Even if, the people interviewed cannot articulate their concerns or participant workers may fail, he suggests the ways to engage human more into the process with the help of insight, observation and empathy. As a critical point of view, one may also consider the possible bias during data collection of qualitative methods (observation) of design researches, which Creswell (2007) mentions as; entry, access type of information collected, potential ethical issues, but mainly due to researcher. However, the cases given in the book are handled by expert design thinkers of IDEO, supposedly less bias might have occurred (Here again, the reader may got the idea that design thinking involves complicated and sensitive processes, especially while collecting data, which could not be handled by a moderate team of small companies). He namely expresses that rather than the aim of design which is creation of products; design thinking shifted the focus to analysis of the relationship between people and products and than to relationship between people to people.

\section{The Methodologies Developed by the Author: Case Studies}

While illustrating important concepts, Brown also explains in the first part of the book that there is no best way to move through the process of design 
thinking. He mentions that there are useful starting points but the continuum of innovation is best thought of a system of overlapping spaces rather than a sequence of orderly steps. Those 3 steps are inspiration which is the problem or opportunity that motivates the search for solution; ideation, the process of generating, developing and testing the ideas and implementation the path that leads the way to market (product, service or strategy). Since design thinking is an exploratory process the nature of this journey is iterative and non-linear.

The 3 spaces of innovation mentioned by Tim Brown, resembles to the Golden Circle Theory in decision-making by Simon Sinek who is well known as a leadership expert with his theory. Sinek, introduces golden circle as a foundation for innovation. However, different than the journey of Design Thinking mentioned by Tim Brown, Simon advises inspiring leaders to start with WHY (motivation similar to inspiration) and step by step move to HOW (process similar to ideation) and WHAT (product similar to implementation) (Chaffey, 2019). So on the contrary to design thinking process stated in the book, the path of Golden Circle is linear since WHAT and HOW are not source of inspiration according to Simon Sinek.

Design Thinking Process (Non-Linear) Theory (Linear)

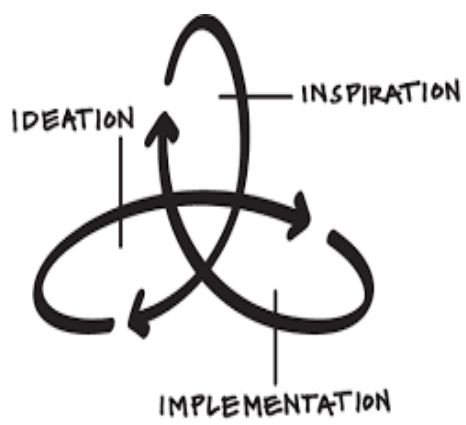

vs Golden Circle

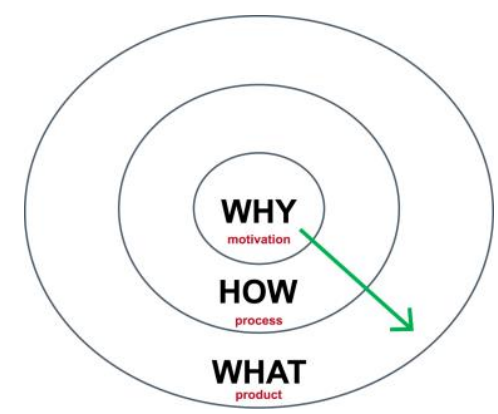

Source 1: Brown T. (2009) Change by Design: How Design

Source 2: https://boscoanthony.com/the-golden-circle/

Thinking Transforms Organizations and Inspires Innovation

In the second half of the book called 'Where do we go from here?' Tim Brown begins to tackle enormous problems. In the early chapters of second part he starts with treating Procter \& Gamble's ability to help housewives better clean their bathrooms, than he lurches to big issues like environmental problems that gives us the insight that IDEO has shifted focus to pay more attention to global human problems. Moving from a 
design brief to earth problems like sustainability, Brown helps the reader to understand the broadness of implication area of design thinking as a problem-solving tool. The book consists of many examples from IDEO, who successfully implies design thinking with its customers. This fact raises in readers mind the question that is: 'Is this a book promoting IDEO as a company rather than design thinking as an innovation tool, if so why there is no sign either about it on the cover or in the title of the book?'

\section{Conclusion}

Although Brown used the comparison method a lot throughout the first chapters of the book between designer and design thinker, business methodologies and design thinking, divergent and convergent thinking; he concluded with saying it is a collaborative process of business oriented designers and professionals adopting creative design thinking into their every level of organization. This collaborative process assesses the viability component of the innovation equation at best. Here it is important to understand what really collaborative design means for Brown. As Kvan (2000) stated collaboration is very demanding issue especially by means of time consumption and also by means of over-emphasized features of computer systems, it is not always the best and most effective way to work together. This view is quite acceptable in our fast moving and competitive world, where actions have to be quick enough to improve or defend our position within the market. Brown rather means co-design, which is explained, by N.Sanders, E. B. \& Stappers, P.J. (2014) as designers and non-designers working together, using making as a way to make sense of the future.

Tim Brown states that everyone can be a design thinker in the first part of the book, but he also confessed in the second part that for long time of period they did not accept business graduates to IDEO team since their divergent thinking and synthesis abilities would not be enough. He uses the comment of Tom Peter that is 'MFA is the new MBA'. However, he doesn't only talk about business graduates to adjust with divergent, synthesisbased methods of design thinking but also the designers becoming business oriented (having MBA). He observes that business thinking is integral to design thinking. For him, design thinking is the area for T-Shaped person, where the vertical axis represents the depth of the skill set that forms core competency. A design thinker is not just an artist or not and number cruncher. Instead they should be skilled and knowledgeable enough about each to be a member of not a multidisciplinary team but of an interdisciplinary team working based on human centered approach. 


\section{References}

Bennett, Nathan and Janes Lemoine (2014), "Crisis Management: What VUCA means for You", Harvard Business Review.

-------- (2014), "What a Difference a Word makes: Understanding Threats to Performance in a VUCA World," Business Horizons, 57. https://doi.org/10.2139/ssrn.2406676.

Camillus, John (2008), "Strategy as a Wicked Problem", Harvard Business Review.

Chaffey, Dave (2019), "Start with Why: Creating a Value Proposition with the Golden Circle Model," Smarting Sights, (accessed on November 21, 2019), [available at: https://www.smartinsights.com/digitalmarketing-strategy/online-value-proposition/start-with-why-creatinga-value-proposition-with-the-golden-circle-model/

Creswell, John W. (2007), Qualitative Inquiry \& Research Design: Choosing Among Five Approaches $2^{\text {nd }}$ ed.

Cross, Nigel (2001), "Designerly Ways of Knowing: Design Discipline versus Design Science", Design Issues, 17 (3), 49-55. https://doi.org/10.1162/074793601750357196

Glaeser, Waltraut (2018). VUCA-world. www.vuca-world.org

Kvan,Thomas (2000), Collaborative Design: What is It?, Elsevier Science B.V, $409-15$

Sanders Elizabeth and Pieter Jan Stappers (2014), "Probes, Toolkits and Prototypes: Three Approaches to Making in Co-designing", International Journal of Co-Creation in Design and the Arts, 10 (1). https://doi.org/10.1080/15710882.2014.888183 